\title{
CORRECTION
}

\section{Correction to: Acid-base equilibria of amino acids: microscopic and macroscopic acidity constants}

\author{
Fritz Scholz ${ }^{1} \cdot$ Heike Kahlert ${ }^{1}$
}

Published online: 13 March 2019

C) Springer Nature Switzerland AG 2019

\section{Correction to: ChemTexts (2018) 4:6}

https://doi.org/10.1007/s40828-018-0060-5

We regret the misprint of two chemical equations in the original article.

The correct equations of the equilibria are as follows:

Equilibrium 10

$$
\mathrm{H}_{2} \mathrm{~A}^{+}+\mathrm{H}_{2} \mathrm{O} \rightleftarrows\left(\mathrm{HA}^{ \pm}\right)_{x}+(\mathrm{HA})_{1-x}+\mathrm{H}_{3} \mathrm{O}^{+}
$$

Equilibrium 11

$$
\left(\mathrm{HA}^{ \pm}\right)_{x}+(\mathrm{HA})_{1-x}+\mathrm{H}_{2} \mathrm{O} \rightleftarrows \mathrm{A}^{-}+\mathrm{H}_{3} \mathrm{O}^{+} .
$$

Publisher's Note Springer Nature remains neutral with regard to jurisdictional claims in published maps and institutional affiliations.

The original article can be found online at https://doi.org/10.1007/ s40828-018-0060-5.

Fritz Scholz

fscholz@uni-greifswald.de

1 Institute of Biochemistry, University of Greifswald, Felix-Hausdorff-Str. 4, 17487 Greifswald, Germany 